\title{
Diagnostic dilemma of primary neonatal iliopsoas abscess
}

\author{
Sampurna Ray ${ }^{1}$, Pranab Kumar Dey ${ }^{1}$, Pankaj Halder ${ }^{2}$ and Arindam Ghosh ${ }^{3^{*}}$ (D)
}

\begin{abstract}
Background: Primary iliopsoas abscess is extremely rare in neonates and overlooked easily. It is potentially curable with surgical drainage and broad-spectrum antibiotics if diagnosed early.

Case presentation: A 13-day-old neonate was presented with a swelling and bluish discoloration on the left thigh and groin. There was a restriction of movement of the left lower limb, and he developed high grade fever later on, during hospital stay. In spite of a great dilemma, we could finally reach the diagnosis of primary iliopsoas abscess, performed surgical drainage, and controlled ongoing sepsis. At 3 months follow-up, the patient was doing well and there was no asymmetry in appearance of movements.

Conclusion: High index of suspicion, vigilant clinical examinations, and targeted laboratory investigations with imaging studies are of paramount importance in establishing its diagnosis. This case highlights the diagnostic difficulties and re-evaluates the representative features of neonatal iliopsoas abscess and its management.
\end{abstract}

Keywords: Iliopsoas abscess, Neonate, Primary, Methicillin-resistant Staphylococcus aureus

\section{Background}

Iliopsoas abscess (IPA) is a rare entity especially in neonates and infants. The varied symptoms are more pronounced in IPA, often resulting in delayed diagnosis and inadequate management. Primary IPA is uncommon and occurred due to staphylococcus bacteremia while secondary IPA may result from septic arthritis. IPA may present with a triad of symptoms: swelling in the abdomen/femoral triangle, reduced mobility of lower limb, and fever [1]. Ultrasonography (USG) should be the investigation of first choice as computed tomography $(\mathrm{CT})$ or magnetic resonance imaging (MRI) is technically difficult to perform in neonates. This condition is highly fatal in neonates due to rapid onset of sepsis. USGguided percutaneous drainage and antibiotic therapy, though advocated, may not be adequate treatment

\footnotetext{
*Correspondence: arindamghosh.mck@gmail.com

${ }^{3}$ Midnapore Medical College and Hospital, Paschim Medinipur, West Bengal, India

Full list of author information is available at the end of the article
}

always. Early surgical drainage often required for complete resolution.

\section{Case presentation}

A 13-day-old neonate was presented with a swelling and bluish discoloration on the left thigh and groin (Fig. 1a). There was reduced movement of the left lower limb. The baby was born by normal vaginal delivery at 37 weeks of gestation with a birth weight of $2.3 \mathrm{~kg}$. There was no history of maternal fever or premature rupture of membrane. USG revealed left-sided large hydrocele and a collection in the left flank area, measuring about $2.5 \mathrm{~mm} \times 3 \mathrm{~mm}$. Needle aspiration from the flank swelling revealed clear fluid. The aspirated fluid from the iliopsoas region showed glucose of $121 \mathrm{mg} / \mathrm{dl}$, protein of $2.5 \mathrm{~g} / \mathrm{dl}$, albumin of $1 \mathrm{~g} / \mathrm{dl}$ and cholesterol of $45 \mathrm{mg} / \mathrm{dl}$, but no microorganism. Blood investigations demonstrated anemia (hemoglobin $9.4 \mathrm{~g} / \mathrm{dL}$ ), total leucocyte count (TLC) of 13,800/cumm with $32 \%$ neutrophils and 64\% lymphocytes, mild thrombocytopenia (platelet 1.3 lakhs/cumm), and C-reactive protein (CRP) value of 3.9 $\mathrm{mg} / \mathrm{dL}$ (normal $\leq 1 \mathrm{mg} / \mathrm{dL}$ ). We started intravenous 


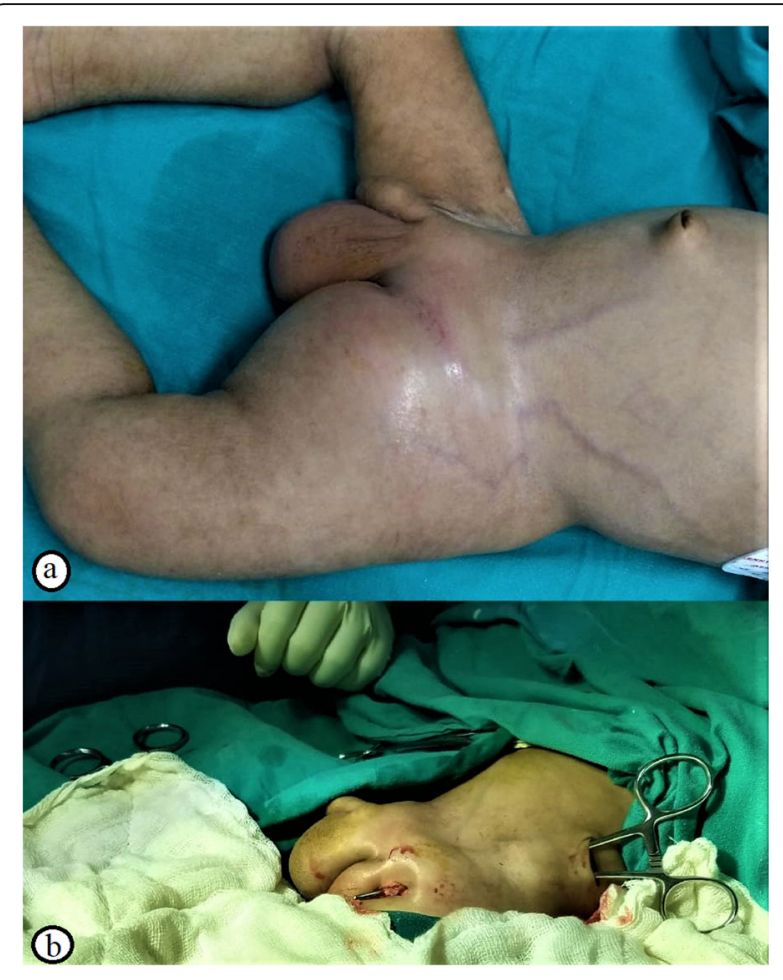

Fig. 1 a Swelling and bluish discoloration on the left thigh and groin. b Operative picture showing incision-counter incision and drainage procedure of IPA

antibiotics in the form of Piperacillin-Tazobactam, Amikacin, and Linezolid as possibility of an abscess could not be ruled out. The patient responded to supportive medical management and we were about to discharge the patient. Surprisingly, the patient developed fever and refusal to feed after three weeks of admission. We shifted the patient in the pediatrics intensive care unit (PICU). The swelling became tense and tender. The child was irritable and started crying with the movement of the left lower limb. Repeat laboratory examinations revealed hemoglobin $8.7 \mathrm{~g} / \mathrm{dL}$, erythrocyte sedimentation rate (ESR) $8 \mathrm{~mm} / 1 \mathrm{st}$ hour, an elevated total leucocyte count (TLC) of $34,000 /$ cumm with $42 \%$ neutrophils, $55 \%$ lymphocytes, and C-reactive protein (CRP) of $5 \mathrm{mg} / \mathrm{dl}$.

New USG showed a hypoechoic space-occupying lesion $(40 \mathrm{~mm} \times 24 \mathrm{~mm})$ in the left iliopsoas region with internal moving contents. We tried another aspiration from the swelling but nothing came out. As the swelling progressed with associated high-grade fever, an MRI of lower abdomen and pelvis was performed which suggested an extremely large, thick-walled abscess measuring $59.7 \mathrm{~mm} \times 31.9 \mathrm{~mm}$ size along the left psoas muscle extending from the level of lower border of the left kidney superiorly up to proximal thigh inferiorly (Fig. 2). In the upper thigh, the abscess was seen to extend from the anterior compartment in to the posterior compartment insinuating in between the muscles. Considering the condition, we discussed with the concerned pediatric surgeon and planned for surgical drainage of the abscess.

Initially, an incision was made in the medial aspect of the thigh where aspiration revealed frank pus. Another counter incision was made under finger guidance in the left flank, piercing the left psoas muscle (Fig. 1b). The whole cavity was then irrigated with normal saline and packed with roller gauze. Pus culture showed growth of methicillin-resistant Staphylococcus aureus (MRSA). However, the result of blood culture was negative. The patient was given meropenem and vancomycin initially which were changed to linezolid for 14 days according to the sensitivity of pus culture. The child responded well with the given treatment. At 3 months follow-up, the patient was doing well and there was no asymmetry in appearance of movements.

\section{Discussion}

IPA is a collection of pus in the iliopsoas compartment. The condition was first described as "psoitis" by Mynter in 1881. It can be classified as primary or secondary, depending on the origin. Primary IPA, common in neonates and occurs as a result of the hematogenous spread of organisms from the occult site. Secondary IPA is common in adults and occurs due to the direct extension of the ongoing infective or inflammatory process near or within the iliopsoas muscle [2]. In the present case, USG could not differentiate it from lymphatic malformation. In spite of intravenous antibiotics, the patient developed fever and poor movement of the left lower limb with raised TLC and CRP after few days.

The important differentials include septic arthritis of the hip, traumatic injury to the hip joint and surrounding structures, osteomyelitis of the femur, abscess at the vaccination site, and lymphatic malformation [3]. Though the clinical differentiation becomes difficult at times but still it is crucial as the approach differs [4]. Delay in diagnosis and inadequate pus drainage may lead to sepsis, mortality, and sequelae of damage to the joints. At this point, CT or MRI must be considered as USG may not differentiate from cystic lymphatic malformation $[5,6]$.

The treatment of IPA is a combination of surgical drainage (percutaneous or open drainage) and broadspectrum antibiotic therapy. In our case as well, antibiotic therapy was started before aspiration of collection and the surgical exploration was done under the coverage of systemic antibiotic. Simple medical management is not always sufficient and pus aspiration, or surgical drainage of abscess may be needed [7]. Many physicians prefer ultrasound-guided percutaneous drainage of the abscess in conjunction with proper antibiotic coverage. 


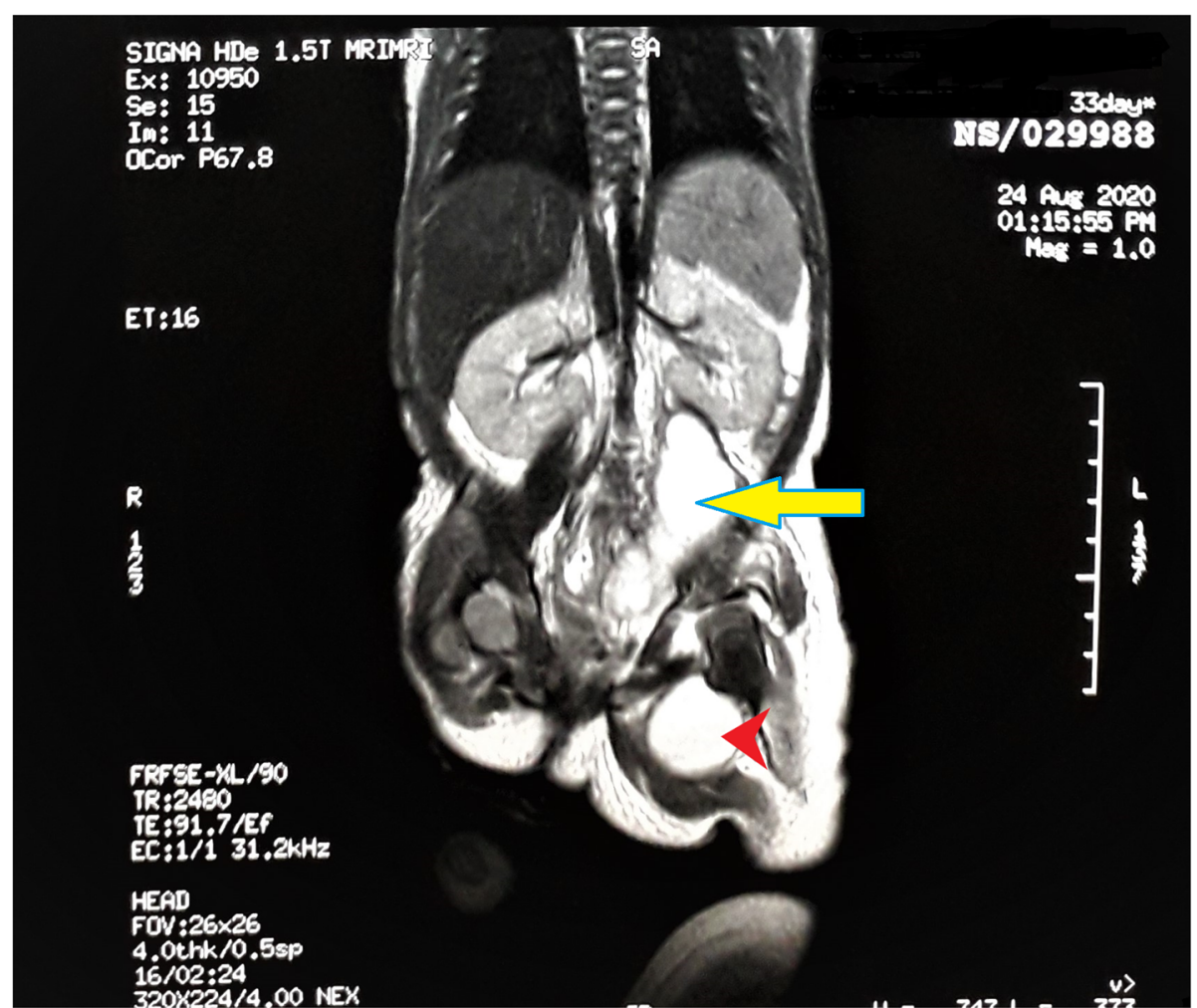

Fig. 2 Magnetic resonance imaging showing thick-walled abscess $(59.7 \mathrm{~mm} \times 31.9 \mathrm{~mm}$ ) along the left psoas muscle (yellow arrow) extending from the level of lower border of the left kidney superiorly up-to left proximal thigh inferiorly (red arrow head)

However, surgical drainage is superior to percutaneous drainage in achieving prompt recovery. Presence of predisposing factors like immune compromise status or MRSA infection needs to be considered for delayed response. Role of immunodeficiency in a case of neonatal IPA is still unclear because most of the studies or reported cases did not reveal such [8].

\section{Conclusion}

This case merits a mention due to the rarity of primary IPA in neonates as well as a diagnostic dilemma. However, high index of suspicion, vigilant clinical examination, laboratory investigations like leucocytosis, raised CRP, and MRI facilitate a prompt diagnosis and proper management without delay. The prognosis stands good with an early recovery with prompt drainage of pus.

\section{Abbreviations}

IPA: Iliopsoas abscess; MRSA: Methicillin-resistant Staphylococcus aureus; PICU: Pediatric intensive care unit

\section{Acknowledgements}

We are grateful to the child's parents who agreed to give consent for this publication.

\section{Authors' contributions}

PH contributed to performing the surgery. SR, PKD, AG contributed to performing early physical examination, general supervision of the case, and post-operative care. SR and AG did the literature search. PKD and AG wrote the manuscript. The authors read and approved the final manuscript.

\section{Funding}

None

Availability of data and materials Not applicable

\section{Declarations}

Ethics approval and consent to participate Yes

\section{Consent for publication}

The parents of the child have given written consent for publishing patient details including pre- and intra-operative images.

\section{Competing interests}

The authors declare that they have no competing interests.

\section{Author details}

'Department of Pediatric Medicine, R.G. Kar Medical College and Hospital, Kolkata, India. ${ }^{2}$ Department of Pediatric Surgery, R. G. Kar Medical College and Hospital, Kolkata, India. ${ }^{3}$ Midnapore Medical College and Hospital, Paschim Medinipur, West Bengal, India.

Received: 28 December 2020 Accepted: 11 May 2021

Published online: 19 July 2021

\section{References}

1. Han Y-M, Kim A-Y, Lim R-K, Park K-H, Byun S-Y, Kim S-H, et al. Neonatal iliopsoas abscess: the first Korean case. J Korean Med Sci. 2015;30(8):1203-6. https://doi.org/10.3346/jkms.2015.30.8.1203. 
2. Nisar MU, Sikander S, Noorain Z, Baig MS, Akhtar N. Primary iliopsoas abscess in a neonate. J Coll Physicians Surg Pak. 2019;29(06):S45-7. https:// doi.org/10.29271/jcpsp.2019.06.S45.

3. Al-Zaiem MM, Bajuifer SJ, Fattani MO, Al-Zaiem FM. Bilateral iliopsoas abscess associated with right hip septic arthritis in a neonate. Saudi Med J. 2014;35(7):743-6.

4. Okan F, Ince Z, Coban A, Can G. Neonatal psoas abscess simulating septic arthritis of the hip: a case report and review of the literature. Turk J Pediatr. 2009:51(4):389-91.

5. Chintakrinda AK, Das B, Dogra S, Mitra D. Primary iliopsoas abscess in an infant: a case report. J Indian Assoc Pediatr Surg. 2018;23:222-4.

6. Pratap A, Tiwari A, Sah BP, Sinha AK, Shakya VC, Niels KG. Infected retroperitoneal cystic lymphangioma masquerading as psoas abscess. Urol Int. 2008;80(3):325-8. https://doi.org/10.1159/000127351.

7. Sham M, Singh D. Neonatal ilio-psoas abscess: report of two cases. J Neonatal Surg. 2014;3(1):4. https://doi.org/10.47338/jns.v3.68.

8. Okada Y, Yamataka A, Ogasawara Y, Matsubara K, Watanabe T, Lane GJ, et al. Ilio-psoas abscess caused by methicillin-resistant Staphylococcus aureus (MRSA): a rare but potentially dangerous condition in neonates. Pediatr Surg Int. 2004;20(1):73-4. https://doi.org/10.1007/s00383-003-1088-0,

\section{Publisher's Note}

Springer Nature remains neutral with regard to jurisdictional claims in published maps and institutional affiliations.

\section{Submit your manuscript to a SpringerOpen ${ }^{\circ}$ journal and benefit from:}

- Convenient online submission

- Rigorous peer review

- Open access: articles freely available online

- High visibility within the field

- Retaining the copyright to your article 